\title{
Cooperative Advertising in a Two-Stage Supply Chain with Network Externalities
}

\author{
Wenhui Li \\ School of Management, Jinan University, Guangzhou, China \\ Email: liwh93@126.com
}

How to cite this paper: Li, W.H. (2019) Cooperative Advertising in a Two-Stage Supply Chain with Network Externalities. American Journal of Industrial and Business Management, 9, 1011-1023. https://doi.org/10.4236/ajibm.2019.94069

Received: March 29, 2019

Accepted: April 25, 2019

Published: April 28, 2019

\section{Copyright $\odot 2019$ by author(s) and} Scientific Research Publishing Inc. This work is licensed under the Creative Commons Attribution International License (CC BY 4.0).

http://creativecommons.org/licenses/by/4.0/

\section{(c) (i) Open Access}

\begin{abstract}
A two-stage game is developed with network externalities where, besides pricing decisions, the retailer and manufacturer can determine their advertising investments and advertising participation rates for each stage. In addition to the full cooperation advertising model, three part cooperation advertising models are established. We develop propositions and insights from the comparison of these models. Our main findings are as follows: 1) the equilibrium solutions critically depend on the effects of network externalities; 2) the optimal choice in a two-stage game is to achieve full cooperation; and 3) a second-best choice for the manufacturer is to share the retailer's advertising in the first stage. Our research results have guiding significance for supply chain member's decision-making in local advertising practice.
\end{abstract}

\section{Keywords}

Game Theory, Cooperative Advertising, Network Externalities, Two-Stage Supply Chain

\section{Introduction}

Recently, cooperative advertising has played a very important role in supply chain coordination. In order to encourage the retailer to advertise more, cooperative advertising strategies are widely adopted by the manufacturer. Companies such as IBM, Apple and Intel all pay a certain percentage of local advertising costs for their retailers [1] [2]. Local advertising has two main advantages over national advertising. On the one hand, the retailer's local advertising can stimulate real-time sales and quickly increase short-term sales [3]. On the other hand, the retailer always has more local market information and could develop more targeted advertising at lower cost. The manufacturer and the retailer can reduce the double marginalization effect in the supply chain through cooperative adver- 
tising, cost sharing and benefit sharing [4]. Then they jointly improve the profitability of the entire supply chain.

Cooperative advertising has become an important topic for business and academia. Many scholars explore the cooperation advertising mechanism between upstream and downstream enterprises by selecting different angles, adopting various methods and constructing mathematical models [5] [6] [7]. Studies can be divided into static games and sophisticated dynamic models [8].

We will discuss cooperative advertising issues in the context of network externalities. In fact, with the rapid development of communication and information technology, the whole society has entered the era of Internet and network economy. More and more products (fax machines, computer hardware, mobile phones, software, etc.) have shown their utility to increase with the number of other users. With the improved feature, Katz first defined this feature as network externalities [9]. Many scholars have studied cooperative advertising under network externalities, such as Kretschmer and Rosner [10]. Network externality is essentially demand-side economics, which is different from traditional economic theory. Obviously, the external performance of the network increases the willingness of consumers to pay, thereby expanding consumer demand. And advertising investment can also increase product demand. In this paper, we focus on how the game players adjust their pricing strategies and cooperative advertising strategies under network externalities. Obviously, this is a new and interesting topic of research.

Most of the literatures on cooperative advertising use a single-stage game model. However, in a real supply chain, cooperative advertising is usually a long-term behavior and attracts the attention of scholars [11] [12]. The first-stage decision will affect the second-stage, then they affect the total supply chain profits. However, the existing literature lacks a two-stage cooperative advertising strategy research under the network externalities. Thus, we have a discussion on cooperative advertising in a two-stage supply chain with network externalities.

The paper proceeds as follows: the next section describes the assumptions and the model structure. Then we have a discussion on these four models, the first model is a cooperative game, and the others are based on a non-cooperative game (the manufacturer as the leader and the retailer as the follower). The interesting results of these four models are analyzed and compared. Finally, the conclusion summarizes the findings.

\section{Assumptions and the Basic Model Structure}

We consider a two-stage supply chain distribution channel with one manufacturer and one retailer. The manufacturer sells the product at a wholesale price $w$ to a retailer, who sells the product to consumers at a retail price $p$. Advertising expenditure $a_{i}$ is also a decision variable for the retailer in stage $i, \quad i \in\{1,2\}$ means Let $a_{i}$ and $t_{i}$ be, respectively, the rate of retailer's local advertising and the manufacturer participation rate or the percentage of the retailer's advertising expenditures that the manufacturer is committed to share in stage $i$. 
As in many other papers in the distribution channel literature, we assume the market demand has three characteristics as follows. Firstly, there is a negative correlation between market demand and price. Secondly, there is a positive correlation between market demand and advertising expenditure while the marginal utility of advertising expenditure is diminishing. Thirdly, there is a positive correlation between market demand and direct network externality. Direct network externality is generated through a direct physical effect of the number of purchasers on the quality of the product. Thus, the demand function can be written as follows:

$$
\begin{gathered}
D_{1}=g-p+\alpha a_{1}+f\left(D_{1}^{e}\right) . \\
D_{2}=g-p+\alpha a_{2}+f\left(D_{1}^{e}+D_{2}^{e}\right) .
\end{gathered}
$$

where $g$ is the market size, $p$ is retail price, $a_{i}$ is retailer advertising expenditure. $\alpha \in(0,1)$ denotes retailer advertising effort factor. $f\left(D_{i}^{e}\right)$ denotes the demand growth of advertising effort. $f\left(D_{i}^{e}\right)$ represents demand growth comes from network externalities when the consumers' expected market sales of the product is $D_{i}^{e}$. We assume that consumers have perfect expectations to the market equilibrium sales in the future that refer to Katz and Srapiro, i.e. consumers have rational expectations [8].

To simplify exposition, we further assume $f\left(D_{i}^{e}\right)=\lambda D_{i}^{e}$, which denotes that the demand generated by the network externality grows linearly with the increase of expected market sales. The slope of those demand lines is $\lambda$, which reflects the intensity of network externalities, and it is called intensity of network externality [13]. Assuming that the impact of consumer's expected market sales on market demand is less than the impact of actual prices on market demand so that $\lambda \in(0,1)$. We assume that the manufacturer and the retailer can influence consumer expectations before buying, i.e. $D_{i}=D_{i}^{e}$ [9]. Thus, the market demand function translates into:

$$
\begin{gathered}
D_{1}=\frac{g-p+\alpha a_{1}}{1-\lambda} . \\
D_{2}=\frac{g-p+\alpha a_{2}+\lambda D_{1}}{1-\lambda}=\frac{g-p+\alpha \lambda a_{1}+(\alpha-\alpha \lambda) a_{2}}{(1-\lambda)^{2}} .
\end{gathered}
$$

Then we assume that all channel members are rational, risk-neutral, and maximize profits. Based on the above hypotheses, the manufacturer profit function in each stage is:

$$
M_{i}\left(w, t_{i}\right)=w D_{i}-\frac{1}{2} t_{i} a_{i}^{2} .
$$

The retailer profit function in each stage is:

$$
R_{i}\left(p, a_{i}\right)=(p-w) D_{i}-\frac{1}{2}\left(1-t_{i}\right) a_{i}^{2} .
$$

We model the channel decision process as a sequential game, with the manufacturer as the leader and the retailer as the follower. Supposing that they both 
collaborate to share advertising expenses, the game proceeds as follows. First, the manufacturer announces the manufacturer participation rate $t_{1} \in[0,1]$ and then the retailer determines the advertising expenditures $a_{1}$ in stage 1 . Subsequently, the manufacturer determines the wholesale price $w$ and the participation rate $t_{2} \in[0,1]$ and then the retailer determines the retail price $p$ and the advertising expenditures $a_{2}$ in stage 2 . Following the sequence of moves explained in Table 1.

\section{The Cooperative Relationship Model}

In this section, we build a centralized cooperative advertising decision model. In the case where $t_{i}=1$, both the manufacturer and the retailer agree to form an alliance. Then they can make decisions together to maximize the total channel profits and jointly determine retail price and advertising expenditure. Thus, the alliance's problem can be written as:

$$
\begin{gathered}
S_{1}^{C}=p\left(\frac{g-p+\alpha a_{1}}{1-\lambda}\right)-\frac{1}{2} a_{1}^{2} . \\
S_{2}^{C}=p\left(\frac{g-p+\alpha \lambda a_{1}+(\alpha-\alpha \lambda) a_{2}}{(1-\lambda)^{2}}\right)-\frac{1}{2} a_{2}^{2} . \\
S^{C}=S_{1}^{C}+S_{2}^{C} .
\end{gathered}
$$

For any $\alpha \in(0,1)$ and $\lambda \in(0,1)$, the alliance's second-stage profits is a strictly concave function of its decision variables $p, a_{2}$ in this stage. From the first-order optimality conditions for the problem in (9), the following expressions can be derived:

$$
\begin{gathered}
a_{2}=\frac{\alpha\left(g+\alpha \lambda a_{1}\right)}{\left(2-\alpha^{2}\right)(1-\lambda)} . \\
p=\frac{g+\alpha \lambda a_{1}}{2-\alpha^{2}} .
\end{gathered}
$$

Then $S_{1}^{C}$ are obtained by substituting the expressions (10) and (11) are given by

$$
S_{1}^{C}=\frac{\left(g+\alpha \lambda a_{1}\right)\left(g\left(-1+\alpha^{2}\right)+\alpha\left(-2+\alpha^{2}+\lambda\right) a_{1}\right)}{\left(-2+\alpha^{2}\right)^{2}(-1+\lambda)}-\frac{a_{1}^{2}}{2} .
$$

Obviously, $S_{1}^{C}$ is a concave function of $a_{1}$. Taking the first derivatives of $S_{1}^{C}$ with respect to $a_{1}$, and setting them to 0 , we have

Table 1. Sequence of moves.

\begin{tabular}{ccc}
\hline & Player & Decision variables \\
\hline Stage 1 & Manufacturer & $t_{1}$ \\
& Retailer & $a_{1}$ \\
Stage 2 & Manufacturer & $w, t_{2}$ \\
& Retailer & $p, a_{2}$ \\
\hline
\end{tabular}




$$
a_{1}=\frac{g \alpha}{2-\alpha^{2}-2 \lambda} .
$$

Substituting (13) into (10), (11) and (9), we have

$$
\begin{gathered}
a_{2}=\frac{\alpha\left(g+\alpha \lambda a_{1}\right)}{\left(-2+\alpha^{2}\right)(-1+\lambda)} . \\
p=\frac{g+\alpha \lambda a_{1}}{2-\alpha^{2}} . \\
S^{C}=\frac{g^{2}\left(2-\alpha^{2}-\lambda\right)}{\left(-2+\alpha^{2}+2 \lambda\right)^{2}} .
\end{gathered}
$$

Proposition 1. $\frac{\partial p^{C}}{\partial \lambda}>0, \frac{\partial a_{1}^{C}}{\partial \lambda}>0, \frac{\partial a_{2}^{C}}{\partial \lambda}>0, \frac{\partial S^{C}}{\partial \lambda}>0$.

Proposition 1 shows that retail price, advertising expenditure, and system profit are positively correlated with network externalities. Obviously, the larger the network externality of the product is, the higher the utility of the consumers gets. Consumers are willing to pay more, so the alliance has an incentive to raise the retail price. In addition, the alliance's unit profit increases as the intensity of network externalities increases. Thus, the alliance has an incentive to increase the advertising expenditure at a level that marginal revenue of unit product equals the marginal cost of advertising investment. Network externalities and advertising effects will work simultaneously, having positive effects on sales volume and bringing benefits to the whole supply chain.

\section{The Leader-Follower Relationship Model}

It is very difficult for enterprises to cooperate completely, but partially cooperative advertising strategy has been widely used in practice. Partially cooperative advertising is also considered to be an effective contract to solve the efficiency loss of supply chain. Thus, in this section, in order to identify whether the partially cooperative advertising strategy could solve the efficiency loss problem in the context of network externalities, we develop a partially cooperative advertising model. The profits for the manufacturer and the retailer can be expressed as a function as follows, respectively:

$$
\begin{gathered}
R_{i}^{D}\left(p, a_{i}\right)=(p-w) D_{i}-\frac{1}{2}\left(1-t_{i}\right) a_{i}^{2} . \\
M_{i}^{D}\left(w, t_{i}\right)=w D_{i}-\frac{1}{2} t_{i} a_{i}^{2} .
\end{gathered}
$$

We divide the decentralized model into three scenarios (Model 1 - Mode 3) based on existing literature. Then we determine the equilibrium of Model 1 Model 3 by backward induction. Throughout this paper, the superscript "D1", "D2" and "D3" means the parameters corresponding to the Model 1, Model 2 and Model 3. Here are the three models and their equilibria.

Model 1: Under conditions $t_{i} \in(0,1)$, the retailer advertises and the manu- 
facturer gives an advertising support to the retailer in each stage.

Furthermore, $\Delta^{\mathrm{I}}, \Omega^{\mathrm{I}}$ and $\theta$ are defined as follows to simplify the expressions later in this paper:

$$
\begin{aligned}
& \Delta^{\mathrm{I}}= 256(1-\lambda)+18 \alpha^{6}(-3+\lambda) \lambda+\alpha^{4}\left(81+231 \lambda-144 \lambda^{2}\right) \\
&+96 \alpha^{2}\left(-3-\lambda+3 \lambda^{2}\right) \\
& \Omega^{\mathrm{I}}= 256(1-\lambda)+27 \alpha^{6}(-1+\lambda) \lambda+\alpha^{4}\left(81+93 \lambda-150 \lambda^{2}\right) \\
&+16 \alpha^{2}\left(-18+4 \lambda+13 \lambda^{2}\right) \\
& \theta^{\mathrm{I}}= 1536(1-\lambda)+243 \alpha^{6}(-1+\lambda)-64 \alpha^{2}\left(39-43 \lambda+3 \lambda^{2}\right) \\
&+6 \alpha^{4}\left(225-249 \lambda+8 \lambda^{2}\right) \\
& \eta^{\mathrm{I}}=24 \alpha^{4}\left(-19-177 \lambda+180 \lambda^{2}\right)-128 \alpha^{2}\left(-22-2 \lambda+23 \lambda^{2}\right) \\
&-18 \alpha^{6}\left(39-156 \lambda+101 \lambda^{2}\right)+2048(-1+\lambda)+243 \alpha^{8}(-1+\lambda)^{2}
\end{aligned}
$$

Then we can determine Stackelberg equilibrium in Model 1 by backward induction:

$$
\begin{gathered}
a_{1}^{D 1}=\frac{g \alpha\left(-10+3 \alpha^{2}\right)\left(8(-2+\lambda)+3 \alpha^{2}(3+\lambda)\right)}{\Delta^{\mathrm{I}}} . \\
a_{2}^{D 1}=\frac{6 g \alpha \Omega}{\left(16-9 \alpha^{2}\right)(1-\lambda) \Delta^{\mathrm{I}}} . \\
t_{1}^{D 1}=\frac{\theta}{\left(16-9 \alpha^{2}\right)^{2}\left(10-3 \alpha^{2}\right)(1-\lambda)} . \\
R^{D 1}=\frac{\left.2 g^{2}\left((-1+\lambda) \eta^{\mathrm{I}}\right) /\left(\Delta^{\mathrm{I}}\right)-\left(2\left(-4+3 \alpha^{2}\right)\left(\Omega^{\mathrm{I}}\right)^{2}\right) /\left(\Delta^{\mathrm{I}}\right)^{2}\right)}{\left(16-9 \alpha^{2}\right)^{2}(-1+\lambda)^{2}} . \\
M^{D 1}=\frac{g \Omega\left(-8+3 \alpha^{2}\right)}{\left(16-9 \alpha^{2}\right)(1-\lambda)^{2}\left(\Delta^{\mathrm{I}}\right)^{2}}-\frac{3 g \Omega\left(4-\alpha^{2}\right)}{2\left(16-9 \alpha^{2}\right)^{2}\left(10-3 \alpha^{2}\right)(1-\lambda)} . \\
+\frac{g\left(8-3 \alpha^{2}\right)\left(\Omega^{\mathrm{I}}\right) D_{1}}{\left(16-9 \alpha^{2}\right)\left(\Delta^{\mathrm{I}}\right)} \\
S^{D 1}=M^{D 1}+R^{D 1} .
\end{gathered}
$$

Model 2: Under conditions $t_{1}=0$ and $t_{2} \in(0,1)$, the retailer advertises in 
each stage, but the manufacturer only supports the retailer's second-stage advertising.

Then we denote

$$
\Delta^{\mathrm{II}}=256(-1+\lambda)-32 \alpha^{2}\left(-9+5 \lambda+3 \lambda^{2}\right)+3 \alpha^{4}\left(-27+3 \lambda+8 \lambda^{2}\right)
$$

and

$$
\eta^{I I}=-256(-2+\lambda)+9 \alpha^{6}\left(-3+\lambda+2 \lambda^{2}\right)-3 \alpha^{4}\left(-85+6 \lambda+40 \lambda^{2}\right)+16 \alpha^{2}(-41+\lambda(7+12 \lambda))
$$

to simplify the expressions later in this paper. Then we can determine Stackelberg equilibrium in Model 2 by backward induction:

$$
\begin{gathered}
a_{1}^{D 2}=\frac{4 g \alpha\left(8(-2+\lambda)+3 \alpha^{2}(3+\lambda)\right)}{\Delta^{\mathrm{II}}} . \\
a_{2}^{D 2}=\frac{6 g \alpha\left(-16+\alpha^{2}(9+4 \lambda)\right)}{\Delta^{\mathrm{II}}} . \\
t_{2}^{D 2}=\frac{1}{3} . \\
w^{D 2}=\frac{g\left(-8+3 \alpha^{2}\right)(-1+\lambda)\left(-16+\alpha^{2}(9+4 \lambda)\right)}{\Delta^{\mathrm{II}}} . \\
\left.p^{D 2}=\frac{3 g\left(-4+\alpha^{2}\right)(-1+\lambda)\left(-16+\alpha^{2}(9+4 \lambda)\right)}{\Delta^{\mathrm{II}}} .\left(-4+3 \alpha^{2}\right)\left(-16+\alpha^{2}(9+4 \lambda)\right)^{2}+2\left(-2+\alpha^{2}(2+\lambda)\right)\left(\Delta^{\mathrm{II}}\right)\right) \\
\left(\Delta^{\mathrm{II}}\right)^{2}
\end{gathered}
$$

Model 3: Under conditions $t_{2}=0$ and $t_{1} \in(0,1)$, the retailer advertises in each stage, but the manufacturer only supports the retailer's first-stage advertising.

Furthermore, $\Delta^{\mathrm{III}}$ and $\Omega^{\mathrm{III}}$ are defined as follows to simplify the expressions later in this paper:

$$
\begin{aligned}
& \Delta^{\mathrm{III}}=8-8 \lambda+\alpha^{6}(-2+\lambda) \lambda+\alpha^{4}\left(2+8 \lambda-6 \lambda^{2}\right)+\alpha^{2}\left(-8-4 \lambda+9 \lambda^{2}\right) \\
& \Omega^{\mathrm{III}}=16(1-\lambda)+2 \alpha^{6}(-1+\lambda) \lambda+\alpha^{4}\left(4+7 \lambda-10 \lambda^{2}\right)+\alpha^{2}\left(-16+2 \lambda+13 \lambda^{2}\right) \\
& \theta^{\mathrm{III}}=24(1-\lambda)+4 \alpha^{6}(-1+\lambda)+\alpha^{2}\left(-40+44 \lambda-3 \lambda^{2}\right)+\alpha^{4}\left(22-24 \lambda+\lambda^{2}\right) \\
& \eta^{\text {III }}=16(-1+\lambda)+2 \alpha^{8}(-1+\lambda)^{2}+\alpha^{2}\left(12+12 \lambda-23 \lambda^{2}\right) \\
& +\alpha^{6}\left(-9+24 \lambda-14 \lambda^{2}\right)+\alpha^{4}\left(8-42 \lambda+32 \lambda^{2}\right)
\end{aligned}
$$

Then we can determine Stackelberg equilibrium in Model 1 by backward induction: 


$$
\begin{aligned}
& a_{1}^{D 3}=\frac{g \alpha\left(-5+2 \alpha^{2}\right)\left(-2+\alpha^{2}+\lambda\right)}{2 \Delta^{\mathrm{II}}} . \\
& a_{2}^{D 3}=\frac{g \alpha \Omega^{\mathrm{II}}}{4\left(-2+\alpha^{2}\right)(-1+\lambda) \Delta^{\mathrm{II}}} . \\
& t_{1}^{D 3}=\frac{\theta^{\mathrm{II}}}{2\left(-2+\alpha^{2}\right)^{2}\left(-5+2 \alpha^{2}\right)(-1+\lambda)} \text {. } \\
& w^{D 3}=\frac{g \Omega^{\mathrm{III}}}{4 \Delta^{\mathrm{III}}} . \\
& p^{D 3}=\frac{g \Omega^{\mathrm{II}}\left(-3+\alpha^{2}\right)}{4\left(-2+\alpha^{2}\right) \Delta^{\mathrm{II}}} . \\
& R^{D 3}=\frac{4 g^{2} \eta^{\mathrm{II}}(1-\lambda)-g^{2}\left(\Omega^{\mathrm{II}}\right)^{2}}{32\left(-2+\alpha^{2}\right)^{2}(-1+\lambda)^{2}\left(\Delta^{\mathrm{II}}\right)} . \\
& M^{D 3}=\frac{g^{2}\left(\eta^{\mathrm{II}}\right)(1-\lambda)-g^{2}\left(\Omega^{\mathrm{II}}\right)^{2}}{16\left(-2+\alpha^{2}\right)^{2}(-1+\lambda)\left(\Delta^{\mathrm{II}}\right)} . \\
& S^{D 3}=M^{D 3}+R^{D 3} .
\end{aligned}
$$

Proposition 2. The three models, where the manufacturer as the leader and the retailer as the follower, has their unique equilibrium with the following properties:
a) In model $1, \frac{\partial p^{D 1}}{\partial \lambda}>0, \frac{\partial w^{D 1}}{\partial \lambda}>0, \frac{\partial a_{1}^{D 1}}{\partial \lambda}>0, \frac{\partial a_{2}^{D 1}}{\partial \lambda}>0, \frac{\partial t_{1}^{D 1}}{\partial \lambda}>0, \frac{\partial t_{2}^{D 1}}{\partial \lambda}=0$.
b) In model 2, $\frac{\partial p^{D 2}}{\partial \lambda}>0, \frac{\partial w^{D 2}}{\partial \lambda}>0, \frac{\partial a_{1}^{D 2}}{\partial \lambda}>0, \frac{\partial a_{2}^{D 2}}{\partial \lambda}>0, \frac{\partial t_{1}^{D 2}}{\partial \lambda}=0, \frac{\partial t_{2}^{D 2}}{\partial \lambda}=0$.
c) In model $3, \frac{\partial p^{D 3}}{\partial \lambda}>0, \frac{\partial w^{D 3}}{\partial \lambda}>0, \frac{\partial a_{1}^{D 3}}{\partial \lambda}>0, \frac{\partial a_{2}^{D 3}}{\partial \lambda}>0, \frac{\partial t_{1}^{D 3}}{\partial \lambda}>0, \frac{\partial t_{2}^{D 3}}{\partial \lambda}=0$.

Proposition 2 shows that in the Stackelberg game, retail price, wholesale price, advertising expenditure are positively correlated with network externalities. In some situations, the manufacturer participation rate is a constant, so it has no connection with network externalities.

Proposition 3. The players' decisions in the first and second stages compare as follows:

a) In Model 1: $t_{1}^{D 1}>t_{2}^{D 1}=\frac{1}{3}, a_{1}^{D 1}>a_{2}^{D 1}$.

b) In Model 2: $t_{1}^{D 2}=0<t_{2}^{D 2}=\frac{1}{3}, a_{1}^{D 1}<a_{2}^{D 1}$.

c) In Model 3: $t_{1}^{D 2}>t_{2}^{D 2}=0, a_{1}^{D 1}>a_{2}^{D 1}$.

To simplify, we assume that the local advertising impact factor and the market size are constant. By changing the strength of the network externalities, we can observe the changes in the two-stage advertising. In order to simplify the results, we have $\alpha=0.5$ and $g=1$. Comparison charts under three models can be eas- 
ily derived using Mathematica 9.0.

The findings of Model 1 shows that the retailer invests more in local advertising and the manufacturer share more advertising cost in the first stage to expand the second-stage baseline demand (see Figure 1). It is interesting that the difference between the two-stage advertising investment becomes smaller and smaller as the network externalities increase. In the context of network externalities, the expanded second-stage demand allows more consumer purchases. Both the manufacturer and the retailer can benefit from it.

The findings of Model 2 shows that the retailer may invest more in advertising in the second stage than in the first stage when the manufacturer only share the second-stage advertising costs (see Figure 2). Although network externalities can expand market demand, but without the manufacturer's cooperative advertising, retailers will tend to be conservative in order to reduce costs.

The findings of Model 3 shows that the retailer invests more in advertising and the manufacturer supports a bigger share of retailer advertising in the first period to expand the second-period baseline demand (see Figure 3). Different from Model 1, the advertising investment in the first-stage is always much higher than the second-stage.

Proposition 4. The comparisons of the manufacture's and retailer's optimal profits for the three different equilibria are as follows:

a) $R^{D 3}>R^{D 1}>R^{D 2}$.

b) $M^{D 3}>M^{D 1}>M^{D 2}$.

The findings of Proposition 4 shows that the retailer invests more in advertising and the manufacturer supports a bigger share of retailer advertising in the first period to expand the second-period baseline demand (see Figure 4 and Figure 5). Different from Model 1, the advertising investment in the first-stage is always much higher than the second-stage.

Unlike the intuitive optimal solution that the manufacturer should continue to share the retailer's advertising. The findings of Proposition 4 show that both the manufacturer and the retailer maximize profit in Model 3, in which the manufacturer only share first-stage advertising costs. And in model 2 when the manufacturer only shares the second-stage advertising, the profits are the lowest.

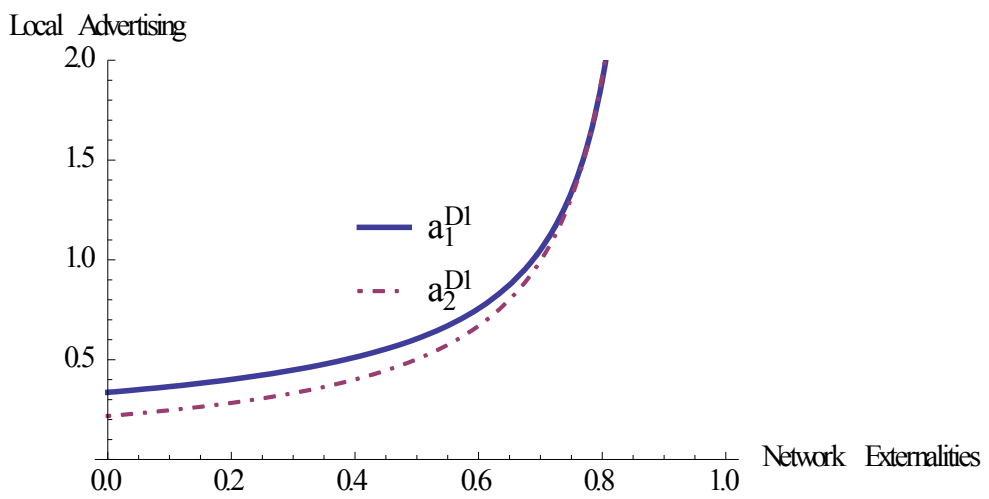

Figure 1. Local advertising under Model $1(\alpha=0.5, g=1)$. 


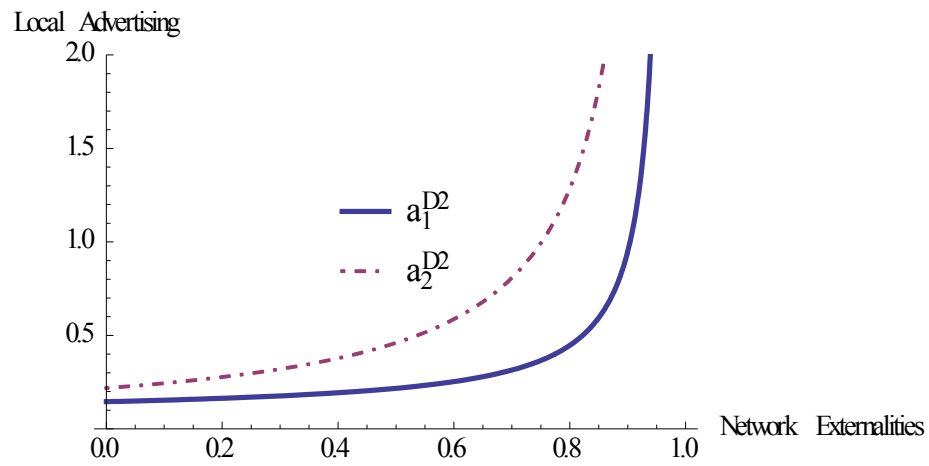

Figure 2. Local advertising under Model $2(\alpha=0.5, g=1)$.

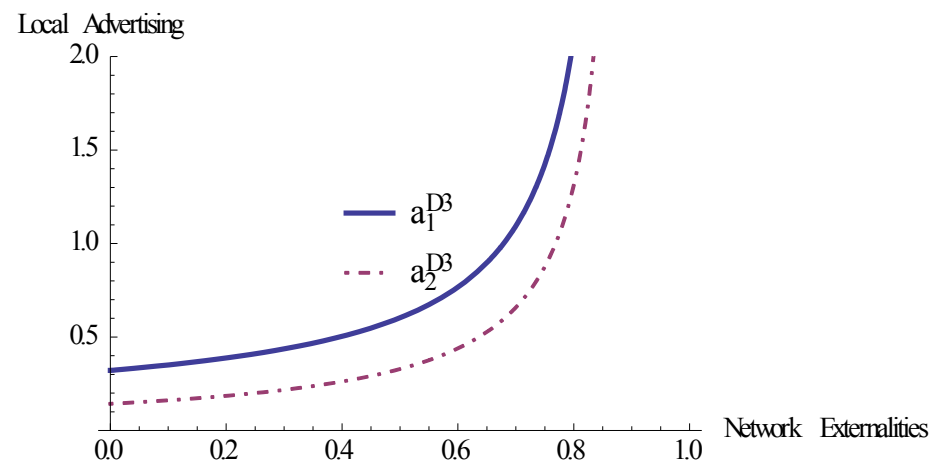

Figure 3. Local advertising under Model $3(\alpha=0.5, g=1)$.

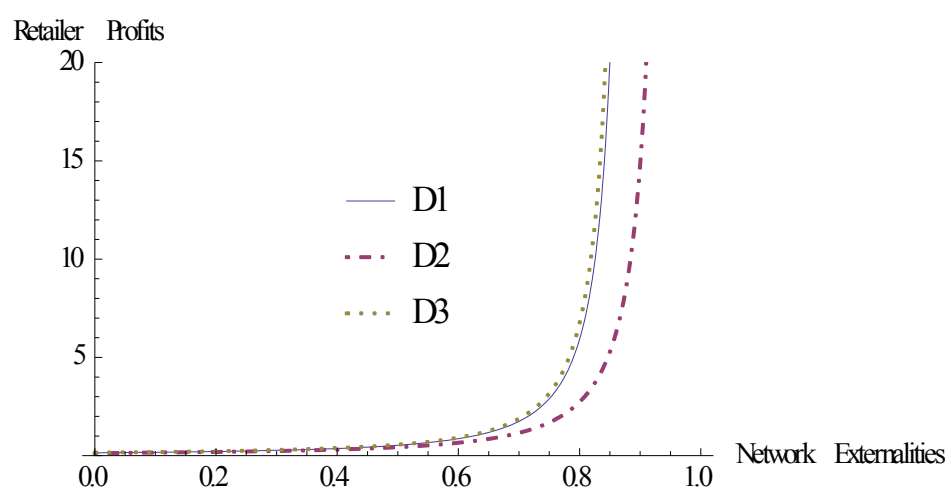

Figure 4. Comparisons of the retailer profits ( $\alpha=0.5, g=1)$.

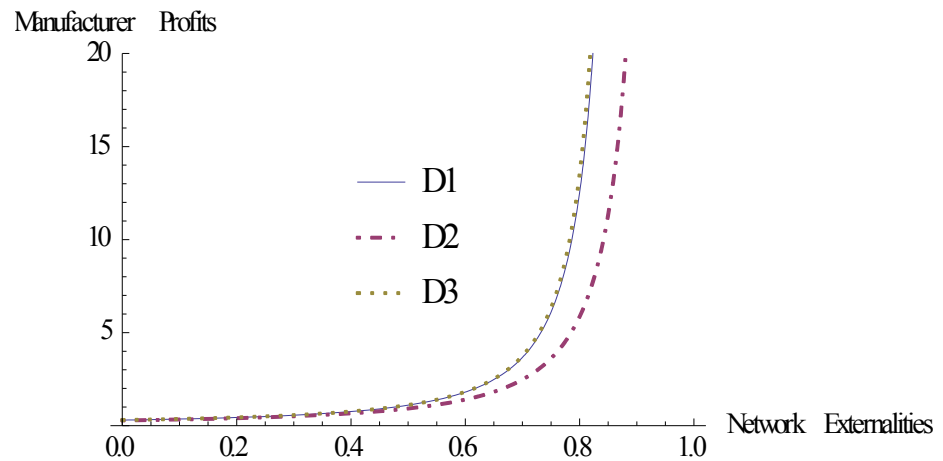

Figure 5. Comparisons of the manufacturer profits ( $\alpha=0.5, g=1)$. 
This is because the existence of network externalities maximizes the effect of the first-stage advertising input. So the basic market demand of the second-stage is expanding. At the same time, they can reduce cost by reducing the advertising or not sharing the second-stage advertising. It has achieved maximum profits for both players.

Proposition 5. The supply chain's optimal profits for the cooperative relationship model and three leader-follower relationship models: $S^{C}>S^{D 3}>S^{D 1}>S^{D 2}$.

The findings of Proposition 5 shows that fully cooperative advertising maximizes supply chain profits (see Figure 6). This is because vertical integration eliminates the wholesale chain and reduces the double marginalization effect. Supply chain members work together for a same goal, and all decision variables reach optimal values.

Thus, we obtain the optimal equilibrium pricing and cooperative advertising strategies in channel coordination in a two-stage game. Using four game-theoretic models, we find that the cooperative model achieves better channel coordination and generates higher channel-wide profits than the non-cooperative, leader-follower model.

\section{Conclusion and Discussion}

This paper analyzes how the manufacturer and retailer should respectively set their cooperative advertising participation rate and advertising investment over a two-stage game. A fully cooperative advertising model and three partly cooperative advertising models are endogenously identified: the manufacturer and the retailer form an alliance (Model C), the manufacturer participates in local advertising in each stage (Model 1); the manufacturer participates in local advertising in the second stage (Model 2); the manufacturer participates in local advertising in the first stage (Model 3). The decision to implement either one of the four models critically depends on the effects of network externalities. In a two-stage game, the optimal choice is to achieve full cooperation. The profits can then be distributed through a contract. Secondly, it is a good choice for the manufacturer to share the first stage of the retailer's advertising. So the two supply chain members can agree to play Model $\mathrm{C}$ and Model 3. The findings of this research

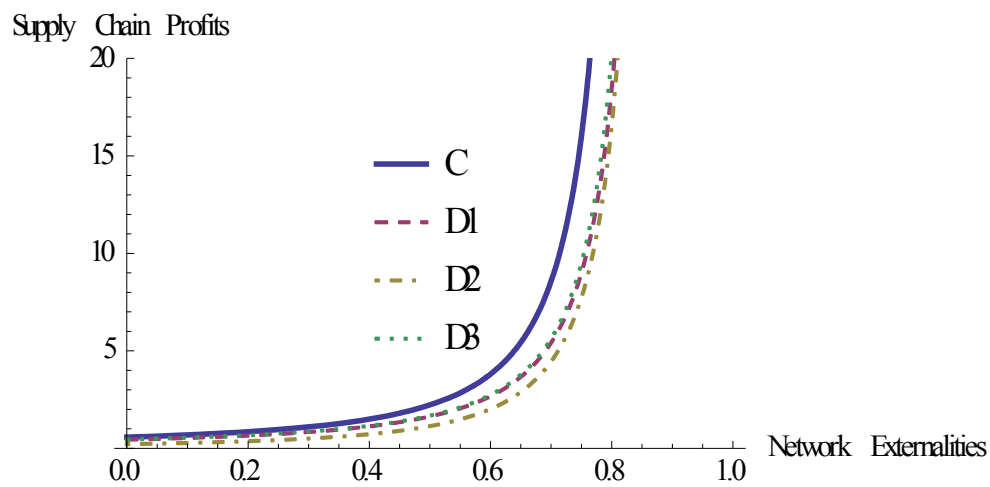

Figure 6. Comparisons of the supply chain profits $(\alpha=0.5, g=1)$. 
extend the existing literature. The findings of this paper also have practical relevance. Managers could better design their pricing and advertising decisions over time.

Our model has some limitations. In order to derive meaningful analytical results, we have simplified our model specification. Some of our assumptions can be relaxed to deal with more complex situations.

\section{Acknowledgements}

The authors are very grateful to the anonymous reviewers for their valuable comments which helped improving the quality of our paper.

\section{Conflicts of Interest}

The author declares no conflicts of interest regarding the publication of this paper.

\section{References}

[1] Pei, Z., Toombs, L. and Yan, R. (2014) How Does the Added New Online Channel Impact the Supporting Advertising Expenditure? Journal of Retailing and Consumer Services, 21, 229-238. https://doi.org/10.1016/j.jretconser.2014.02.004

[2] Yang, J., Xie, J., Deng, X. and Xiong, H. (2013) Cooperative Advertising in a Distribution Channel with Fairness Concerns. European Journal of Operational Research, 227, 401-407. https://doi.org/10.1016/j.ejor.2012.12.011

[3] Martín, H., Guiomar, S. and Simon, P. (2017) An Integrative Framework of Cooperative Advertising: Should Manufacturers Continuously Support Retailer Advertising? Journal of Business Research, 12, 67-73. https://doi.org/10.1016/j.jbusres.2016.07.005

[4] Xie, J. and Wei, J.C. (2009) Coordinating Advertising and Pricing in a Manufacturer-Retailer Channel. European Journal of Operational Research, 197, 785-791. https://doi.org/10.1016/j.ejor.2008.07.014

[5] Huang, Z. and Li, S.X. (2001) Co-Op Advertising Models in Manufacturer-Retailer Supply Chains: A Game Theory Approach. European Journal of Operational Research, 135, 527-544. https://doi.org/10.1016/S0377-2217(00)00327-1

[6] Li, S.X., Huang, Z., Zhu, J. and Chau, P.Y. (2002) Cooperative Advertising, Game Theory and Manufacturer-Retailer Supply Chains. Omega, 30, 347-357. https://doi.org/10.1016/S0305-0483(02)00051-8

[7] He, X., Prasad, A. and Sethi, S.P. (2009) Cooperative Advertising and Pricing in a Dynamic Stochastic Supply Chain: Feedback Stackelberg Strategies. Production and Operations Management, 18, 78-94. https://doi.org/10.1111/j.1937-5956.2009.01006.x

[8] Aust, G. and Buscher, U. (2014) Cooperative Advertising Models in Supply Chain Management: A Review. European Journal of Operational Research, 234, 1-14. https://doi.org/10.1016/j.ejor.2013.08.010

[9] Katz, M.L. and Shapiro, C. (1985) Network Externalities, Competition, and Compatibility. The American Economic Review, 75, 424-440.

[10] Kretschmer, T. and Rosner, M. (2010) Increasing Dominance-The Role of Advertising, Pricing and Product Design. Discussion Papers in Business Administration. 
https://ssrn.com/abstract $=1545754$

https://doi.org/10.2139/ssrn.1545754

[11] Sigué, P. and Chintagunta, S. (2009) Pradeep Advertising Strategies in a Franchise System. European Journal of Operational Research, 198, 655-665.

https://doi.org/10.1016/j.ejor.2008.09.027

[12] Cai, G.S., Chiang, W.C. and Chen, X.F. (2010) Game Theoretic Pricing and Ordering Decisions with Partial Lost Sales in Two-Stage Supply Chains. International Journal of Production Economics, 130, 175-185. https://doi.org/10.1016/j.ijpe.2010.12.007

[13] Prasad, A., Venkatesh, R. and Mahajan, V. (2010) Optimal Bundling of Technological Products with Network Externality. Management Science, 56, 2224-2236. https://doi.org/10.1287/mnsc.1100.1259 